\title{
LA NACIÓN CÍVICA EN EL DISCURSO DE LA GENERACIÓN DE 1837. LOS USOS DE 'CIVISMO', 'CIVILIDAD'Y 'CIVILIZACIÓN' EN JUAN BAUTISTA ALBERDI Y DOMINGO FAUSTINO SARMIENTO
}

\author{
Susana Villavicencio ${ }^{1}$ \\ Gabriela Rodríguez ${ }^{2}$ \\ Universidad de Buenos Aires \\ susanavillavicencio@gmail.com \\ rodriguezgabriela@conicet.gov.ar \\ silphidis@hotmail.com
}

\begin{abstract}
Resumen
El objeto de este trabajo es abordar la idea de nación cívica, un concepto político clave en la producción discursiva de la Generación de 1837, cuyo poder de interpelación ha persistido en momentos más recientes de la historia Argentina.

Para ello, se analizarán con las herramientas heurísticas de la historia conceptual (Koselleck, Skinner) los usos de 'civilidad', 'civismo', 'civilización', 'patria' y 'nación' en un corpus específico de la producción de Juan Bautista Alberdi y Domingo Faustino Sarmiento. Nuestra hipótesis de lectura es que, para comprender las diferencias entre estos dos planteos y las tensiones internas de cada uno de ellos, hay que problematizar sus representaciones discursivas, a partir del carácter polisémico y polémico de la nación cívica, donde conviven formas de la politicidad muchas veces contrapuestas, como el republicanismo cívico y la dominación civilizatoria.

En ese marco, adquiere mayor relevancia una pregunta filosófico-política cuyo sentido se reafirma en el contexto del Bicentenario: ¿cuáles son las implicancias contemporáneas de un discurso político-generacional que pretendió crear una nación para el desierto Argentina?

Palabras Clave: nación cívica, civilidad, civismo, civilización.
\end{abstract}

Abstract

The main object of this paper is analyze to the notion of civic nation, a concept and a politic representation which is fundamental in the production of the Generation of 1837 in Argentina The interpellation power of this concept still persists in recent moments of argentine history.

1 Profesora de Filosofía y Ciencia Política, Carrera de Ciencia Política, e Investigadora del Instituto Gino Germani, Universidad de Buenos Aires.

2 Investigadora del Instituto Gino Germani/CONICET, Carrera de Ciencia Política. Universidad de Buenos Aires. 
To this end, we shall study, with the heuristic tools of Conceptual and Intellectual History, the uses of 'civility', civism', 'civilization', 'patria' and 'nation' in an specific corpus of Juan Bautista Alberdi and Domingo Faustino Sarmiento's production. Our reading hypothesis is that for understanding the differences between these two interpretations of the civic nation and the internal tensions that each proposition has is necessary to question their discursive representations. Because it is inside these representations of civic nation we can identify oppositional conceptions of politics such as the civic republicanism and the domination of the civilization.

KEY WORDS: civic nation, civility, civism, civilization.

\section{La idea de nación}

RRA ¿Qué es una nación? El interrogarnos por el sentido de la nación pretende romper con la naturalización que el uso hagiográfico o ideológico ha dado a este término, tan difundido como confuso en la historia política latinoamericana. Esta pregunta, que evoca la célebre conferencia pronunciada por Ernest Renan en la Sorbonne en 1882, reenvía, por el contrario, a la necesaria explicación de su no naturalidad, de su compleja formación, de su radical historicidad. ¿Qué es una nación? Formulada en el contexto del Bicentenario de la Revolución de Mayo, la pregunta pone en cuestión asimismo el mito del origen por el cual emergemos de la ruptura del vínculo colonial con todos los atributos de la nación moderna.

La historiografía reciente exhibe continuidades más que rupturas, y da lugar a una lectura que corre el velo sobre el largo interregno entre la independencia y las primeras experiencias constitucionales de organización política. En ese lapso de encarnizadas luchas civiles y de intentos fallidos de republicanizar el antiguo territorio colonial, la nación cívica fue más un proyecto que una realización efectiva. Finalmente, responder esta pregunta, a pesar de su actualidad, nos lleva a la cuestión inactual de un discurso particular sobre la formación de la nación argentina, aquel que de modo contradictorio, y a veces sospechosamente convergente, pronunciaran en esos albores dos hombres fundamentales para nuestra historia nacional: Juan Bautista Alberdi y Domingo Faustino Sarmiento.

Miembros de la generación del 37, autodenominada "la nueva generación", tomarán distancia respecto de los "errores" de sus predecesores y llevarán a cabo la primera reflexión consciente sobre el sentido de la nación. La representatividad de cada uno de ellos respecto de una narrativa generacional puede justificarse, positiva o negativamente, con diferentes argumentos. Optamos por mostrar las tensiones que aloja la idea de nación cívica que fueron forjando a la par de sus acciones políticas. En ese sentido postulamos un paralelismo entre una historia personal y la historia del relato de la nación argentina que cada uno de ellos nos cuenta. Relato que contiene las mismas tensiones y contradicciones que la vida misma. 
¿Qué significa nación cívica? En primer lugar entendemos que la idea de nación cívica constituye un filosofema, y que como tal, representa el punto de encuentro y (des) encuentro entre una filosofía con valor universal o al menos cosmopolita, con un discurso sobre (y para) la construcción de una nación particular. Como afirma el filósofo Jacques Derrida, "la auto-identificación nacional tiene siempre la forma de una filosofía que por ser representada por tal o cual acción, no deja de ser una cierta relación a la universalidad de lo filosófico" (Derrida 1987, p. 29). Podemos admitir, entonces, que la idea de nación adjetivada civilizada y cívica, que recorre las reflexiones de las elites políticas en un momento de confrontaciones violentas e inacabables, sea un filosofema contenido en los proyectos que esas mismas elites opusieron a otras formas políticas que representaban para ellos la continuidad del orden colonial, o los obstáculos que la naturaleza americana oponía al proceso de civilización. Ese proyecto de nación se nutrió, como analizaremos, del legado de las revoluciones modernas, de la centralidad del contrato como núcleo del lazo social, y de las nuevas formas de legitimidad política.

El segundo aspecto a destacar es que la nación cívica opera como un concepto político que permite analizar discursivamente los usos de la 'nación' en Alberdi y Sarmiento sin separarlos de su sentido práctico, pero sin reducirlos tampoco a un determinado resultado histórico del proceso político institucional que protagonizaron ${ }^{3}$. Así, la clásica oposición de la civilización y la barbarie se resignifica a partir de las tensiones del republicanismo cívico de Sarmiento, en el que conviven el humanismo y la añoranza de la libertad de los antiguos con una pulsión de dominio autoritaria de todo aquello que escape al ideal homogenizador de la nación. Asimismo, aunque preso de distintos dilemas, el discurso de Juan Bautista Alberdi se ve atravesado por la tensión entre la civilización autorregulable y la necesidad de un poder fuertemente centralizado. A esto se suma un patriotismo sentimental que recusa teóricamente el ideal clásico del civismo antiguo, pero que quiere crear un nuevo civismo adaptando al mundo moderno los valores irrenunciables que dejó la Revolución de Mayo como legado.

La orientación filosófico política de nuestra lectura de Sarmiento y Alberdi se revela en tres postulados que estructuran la argumentación de esta ponencia. Primero, el ocuparse de la construcción discursiva de la nación en Alberdi y Sarmiento significa ante todo interrogarnos por su proyección presente. Problematizar su legado, antes que anatemizarlo o alabarlo, puede ayudarnos si no a responder, a actualizar la pregunta: Argentinos, ¿de dónde venimos y a dónde vamos? Segundo, gracias a los aportes de la Historia Conceptual e Intelectual y de la Teoría Política podemos reconciliar los sentidos históricos de los conceptos y reconocer incluso la materialidad de sus empleos y expresiones. En virtud de eso podemos afirmar que este recorrido por los usos de la

3 Seguimos aquí la línea argumental y conceptual desarrollada en el libro colectivo Perfilar la Nación Cívica en la Argentina (Villavicencio, Pacecca: 2008). Asimismo en este trabajo recuperamos y ampliamos una conceptualización de la nación cívica como sintagma sintetizador de dos vocablos, civismo y civilidad, que Pilar Bernal González de Quiroz (1999, pp. 328-9) desarrolló en su estudio histórico de la sociabilidad rioplatense entre 1852 y 1862. 
nación cívica en Sarmiento y Alberdi aportan no solamente a la comprensión histórica de nuestras tradiciones políticas sino también a la comprensión de los sentidos de la nación como concepto político clave de la historia política moderna. Finalmente, es desde la Filosofía Política que nos proponemos dialogar con estos autores e interrogarlos desde un lugar diferente al que ellos mismos, o sus interlocutores han pensado para plantear juntos la pregunta ¿qué es la política?

\section{Alberdi: El triunfo de la civilidad sobre el civismo}

"Cada uno concibe la patria a su modo, cada uno se hace de su esfera una idea arreglada a la esfera del espíritu. De modo que la idea de la patria es, de todas las ideas sociales, la más móvil, la más varia, la más progresiva y perfectible. Para el campesino, la patria es el valle que lo ha visto nacer. (...) Y para los espíritus vastos y serios que saben no estacionarse en el estrecho círculo de la nación, para los Rousseau, los Fenelon, los Saint-Simon, los Leroux, los Lamenair (sic) [la patria es la humanidad: el pueblo es el género humano". Alberdi, Escritos Póstumos, tomo XIII (2002:27)

Nuestra comprensión de los usos de la nación en el discurso de Juan Baustista Alberdi y de los modos en que estos van mutando a lo largo de su trayectoria parte de un supuesto específico que remite a la historia conceptual de larga duración de la nación ${ }^{4}$ (Rodríguez 2008, pp. 50-54). Este supuesto es que la nación, especialmente en su versión cívica, participa de un campo semántico donde interviene como concepto diferente pero por momentos complementario de la "patria", pero también de las nociones de 'civismo', 'civilidad' y 'civilización'. El civismo es el anclaje con la tradición o las tradiciones republicanas y los no poco complejos usos político-discursivos de la 'república'. La civilización se relaciona, más allá del antagonismo con la barbarie, con la idea de un poder autoridad que domina (Estado o estatalidad), pero también con una sociedad civil modernamente democrática (en el sentido tocquevilliano de Estado social) que paulatina y liberalmente va necesitar cada vez menos del control o la regulación de lo político. Sin embargo, esa civilización no se logra automáticamente por obra del desarrollo económico sino que necesita contar con hombres aptos para realizarlo. La cualidad que los define es la civilidad. Esta civilidad, a diferencia de Sarmiento, Alberdi cree que se adquiere menos por la educación formal que por el aprendizaje práctico y tampoco espera se transforme necesariamente en ciudadanía política. El tucumano se conforma con que sea plenamente civil.

$4 \quad$ La metodología analítica de la sección que se ocupa de Alberdi se sirve de una combinación de la Historia Conceptual (Kosselleck 1998) y la Historia Intelectual en su versión de la Escuela de Cambridge (Skinner), adaptadas a los objetivos y estructura de esta presentación. 
Una vez presentado este campo semántico general, enunciamos nuestra hipótesis de lectura que se aplica especialmente a los primeros y a los últimos textos de la producción de Juan Bautista Alberdi. Existe en la trayectoria de Alberdi un paulatino cambio en la valoración de la noción de "patria", que afecta especialmente su relación con la 'nación', transformando lo que era un vínculo complementario en una oposición contrario asimétrica 5 . Sin embargo, este cambio no significa que no persistan o se profundicen apropiaciones específicas de ambos conceptos que explican por qué, sin renunciar del todo al patriotismo por su vínculo sentimental con la Revolución de Mayo y el rol que su propia familia cumplió en ella ${ }^{6}$, la nación alberdiana será civil antes que cívica.

De la patria a la nación, de la nación cultural a la civil

Tanto el Fragmento Preliminar al Estudio del Derecho como La omnipotencia del Estado es la negación de la libertad individual fueron redactados y difundidos en momentos importantes de la trayectoria intelectual de Juan Bautista Alberdi. El primero fue escrito entre fines de 1836 y principios de 1837, fecha de datación del prefacio (Alberdi (1837) 1954, p. 9), y constituye la presentación de un conjunto de temas y posiciones respecto de los mismos que serán recuperados en otras intervenciones de juventud como el discurso de apertura del Salón Literario ( "Doble Armonía entre el objeto de esta institución, con una exigencia de nuestro desarrollo social; y de esta exigencia con otra general del espíritu humano") o los artículos de La Moda. Además, este texto publicado en enero de 1837 adelanta, en algunos aspectos, el programa de la Generación del 37 que quedará plasmado en el Dogma Socialista. Pero ante todo, el Fragmento es una primera expresión de la especificidad teórica y política del pensamiento alberdiano.

La Omnipotencia del Estado es el producto de otro tiempo. El célebre autor de las Bases..., pero también el enemigo político de Buenos Aires, el mitrismo y el ex presidente Sarmiento, regresa a la ciudad donde pasó su juventud decidido a congraciarse al menos parcialmente con ello. Alberdi es convocado por los nuevos jóvenes que dicen querer honrarlo con una conferencia en la Facultad de Derecho, dictada el 24 de mayo de 1880. Fue la primera enunciación pública de La omnipotencia del Estado es la negación de la libertad individual, donde hizo explícitas las influencias de Adam

5 Este tipo de oposición implica que los conceptos que se relacionan no solo se distinguen porque implican universos de experiencia distinguibles entre sí, sino también porque se produce entre ellos un matiz evaluativo (Koselleck 1993, p. 249). La caracterización positiva de uno implica la descalificación o valoración negativa del otro.

6 Su padre es un inmigrante vizcaíno que se instala como comerciante en Tucumán y abraza fervientemente, como apasionado lector de El contrato Social de Rousseau, la causa de los revolucionarios de mayo. Vale recordar también que Alberdi nace el 29 de agosto 1810 y su madre muere en el parto, por lo que solía decir que el era hijo de la revolución. 
Smith, Spencer y Fustel de Coulanges en su peculiar "liberalismo" (Mayer 1963, p. 878; Alberdi, "Memorias", EP XV, 2002, p. 155). Poco tiempo después, federalización de Buenos Aires mediante, Alberdi regresa a Europa porque, aunque cumplido su deseo de destruir el sistema ciudad metrópoli que regía desde la Colonia, no se siente del todo en su lugar.

Estas dos intervenciones, que marcan el comienzo y el final de la biografía personal e intelectual de Alberdi, van a ser privilegiados en el análisis del corpus que hemos elegido para tratar de abordar la construcción discursiva de la nación en este autor. Esta prioridad se basa en que ambos permiten observar cómo la relación entre 'nación' y 'patria' en Alberdi pasa, de ser una relación contraria simétrica, a veces superpuesta y otras, complementaria, a derivar poco a poco en una polaridad asimétrica donde la patria, el patriotismo y el falso nacionalismo (sinónimo de este último) constituyen los polos negativos. Sin embargo, para comprender esta mutación conceptual es necesario tener en cuenta otros textos cuyo análisis en detalle no podemos ofrecer aquí. Solamente mencionaremos El Crimen de Guerra (1870), donde se ve claramente el triunfo de la civilidad civilizada sobre el civismo, y para justificar la postura enunciativa que asume Alberdi en su discurso sobre la nación se hará una breve referencia a textos de un registro más literario, como Peregrinación Luz de Día o Viaje y aventuras de la Verdad en el nuevo Mundo, de 1871, o incluso el juvenil El Gigante Amapolas (1842).

Empecemos analizando algunos de los sentidos de 'patria' y 'nación' en el Fragmento Preliminar y el modo en que son readoptados y resignificados en la producción posterior de Alberdi, para luego detenernos en el campo semántico de la civilidad, la civilización y el civismo y el modo en que estas tres nociones aportan a la versión alberdiana de la nación cívica. El primer contexto de la "nación” en el Fragmento refiere a la nación cultural (Alberdi 1954, p. 186), incluso a pesar de que su fuente de referencia no sean los alemanes, sino los románticos y socialistas (saint-simonianos) franceses y, por ende, ya se haya producido un proceso de repolitización de esta noción. En consecuencia, en una primera acepción, y con una connotación positiva que replica otros argumentos preexistentes, la nación se define como el espacio de realización de la revolución cultural, que es la condición de posibilidad de la verdadera emancipación espiritual que no pudo realizarse ni con anterioridad ni paralelamente a la independencia política (Alberdi 1954, pp. 52-3). Porque:

"una nación no es libre sino cuando ha gastado, por así decirlo, el verbo ser: cuando le ha aplicado a todas las fases del espíritu, y ha comprendido qué es el hombre, qué es el pueblo, cuál es su misión, su rol su fin” Alberdi (1954, p. 254).

La patria no es convocada tantas veces como lo será en La Omnipotencia, pero sus apariciones (no más de 6 en las 261 páginas) son muy significativas. El primer argumento donde se utiliza este concepto es una nota al pie que condena el excesivo voluntarismo de la Generación de Mayo y la Generación Unitaria, cuya fuente de inspiración era el liberalismo abstracto benthamiano (Alberdi 1954, p. 62). Pero esta referencia de clara 
connotación a Pierre Leroux es la única ${ }^{7}$. Tanto en la cita del epígrafe que antecede este apartado como en la referencia de la página 251 de la edición de referencia, se cambia la valoración y se emplea 'patria' como sinónimo de compromiso con el espíritu público, por encima de la lucha partidista con la que era asociada en la primera aparición. Esta será la visión de la patria y el patriotismo que Alberdi se adjudicará siempre a sí mismo y a sus amigos (sobre todo a Gutiérrez) contra aquellos impostores, primero Rosas, luego Sarmiento y Mitre, que lo acusan de traición (Alberdi, EP XI 2002, pp. 164, 181, 195; Alberdi, El gigante... 1920, pp. 1, 4, 19).

Sin embargo, así como la reivindicación de la soberanía popular se tensiona por la necesidad de "educar" al pueblo que deje de ser plebe facciosa (Alberdi 1954, pp. 72, 76-7), la 'patria' se resignifica cuando se asocia a un gobierno paternal, que educa y mejora, como en el hogar familiar, las costumbres de "sus hijos" (Alberdi, 1954, p. 185). Y aunque, aparentemente, esta tarea legislativa que se inspira en las lecciones platónicas (e, incluso, de Rousseau) parezca ser positivamente valorada, la co-presencia de otros argumentos relativiza esta evaluación. Por un lado, el cristianismo aporta a la humanidad una cuota de sensibilidad personal antes desconocida (Alberdi 1954, p. 214). Por el otro, la asimilación de la libertad a la "potestad de sí mismo" implica la existencia de un derecho preexistente al poder civil, que lo único que puede hacer es consagrar en las normas positivas (Alberdi 1954, p. 20). Ambas afirmaciones comienzan a insinuar el carácter anacrónico del patriotismo de cuño antiguo.

Esta cuestión es clave para nuestra interpretación. A pesar de su apego a la retórica "socialista" (saint-simoniana, mazziniana) que pretende reconciliar lo individual con lo social y lo voluntario con las creencias arraigadas en una noción diferente de progreso a la acuñada por los ilustrados, para Alberdi la libertad individual es un valor casi sagrado (Alberdi 1954, p. 178). Y es en esta concepción negativa de la libertad donde puede verse una continuidad importante en su desarrollo teórico, que le permitirá, por un lado, defender hobbesianamente la autoridad como garante de la seguridad necesaria para el desarrollo de las capacidades individuales y, por el otro, a reivindicar la autorregulación social en todas aquellas esferas que no tengan que ver con el ejercicio ultima ratio de la soberanía.

En este sentido, la relación entre patria y nación en el Fragmento se articula con un ideal civilizatorio que requiere, por un lado, del civismo para transformar, educación e ingeniería electoral mediante, al pueblo real en un legítimo soberano electoral, y por el otro, de una civilización que realice un ideal de progreso todavía solidario. Sin embargo, ya aparecen algunas tensiones. Y estas apuntan a una concepción fuertemente paternalista del poder autoridad, por una parte, y por la otra, a la postulación de una libertad negativa que se realiza con plenitud en el ámbito de la sociedad civil autorregulada.

Alberdi reproduce las críticas de Pierre Leroux a la abstracción del siglo XVIII, que le impidió concretar una idea acabada de progreso. Leroux, Revue Encyclopédique (oct.-dic. 1833: I-LXXI). 
Como sintetiza acertadamente Natalio Botana (1997, p. 442), "El discurso sobre La omnipotencia del Estado... es una meditación pesimista acerca del tenaz arraigo de la libertad antigua en las sociedades sudamericanas". Este discurso se encuentra fuertemente inspirado en el libro La Ciudad Antigua, de Fustel de Coulanges, texto escrito para cuestionar las relecturas del mundo antiguo realizadas en Francia, con el objeto de justificar ideológicamente los regímenes políticos modernos. La argumentación de de Coulanges se sustenta en la "versión fuerte" de la división que realiza Benjamin Constant entre la libertad de los antiguos y la libertad de los modernos. Para el autor de De la Liberté des Anciens comparée à celle des Modernes, si bien la libertad antigua no se corresponde con las condiciones de existencia de la vida moderna (grandes Estados, comercio, espíritu individual), esto no significa que todo lo que esté asociado a la modernidad sea positivo. En cambio, para de Coulanges ambas libertades son totalmente incompatibles, y la moderna es necesariamente superior a la antigua, que solo era posible en regímenes teológico-políticos, categoría a la que sin duda pertenecen, en su análisis, las polis griegas, donde el individuo está a merced de la omnipotencia del "Estado".

Este es el punto de partida del discurso de Alberdi. Por ello, 'patria' y 'patriotismo' se resemantizan negativamente, al asociarse con un poder estatal omnímodo, que impide el goce de la libertad individual, que no es otra cosa que la libertad civil de los hombres industriosos como William Wheelwright, que se preocupa más por ganar dinero y ejercer libremente su culto, que por participar en la sociedad política (AlberdiBotana, 1997, pp. 420-424).

Una frase sintetiza claramente el peligro de este elogio a una forma antigua de patriotismo que ponía su eje en la heroicidad bélica y subordinaba la libertad individual a un "Estado" omnímodo que pretendía controlar incluso el foro íntimo de hombres hasta en el plano de las creencias religiosas ${ }^{8}$ :

"Una de las raíces más profundas de nuestras tiranías modernas en Sudamérica es la noción grecorromana del patriotismo y la patria, que debemos a la educación medio clásica que nuestras universidades han copiado de Francia." Alberdi ([1880]1996, p. 299).

Pero ¿cuáles son los males de la patria antigua que por suerte, a decir del historiador francés de la antigüedad, Fustel de Coulanges y de Alberdi, la modernidad nos hizo felizmente abandonar? Las siguientes citas donde Alberdi rerpoduce, mencionando o no la fuente, los argumentos esgrimidos en La ciudad Antigua, llaman la atención no solo por el anacronismo de hablar de estatalidad en una sociedad política premoderna sino también por la intencionalidad política directa que tienen estas referencias aparentemente tan eruditas e intelectualmente distanciadas:

8 Cabe recordar que este temor a una concepción militarista del patriotismo y la heroicidad son criticados también en el Dogma Socialista, aunque este texto en cuya escritura Alberdi participó, esté mucho más impregnado de los ideales del humanismo cívico que los escritos del tucumano. 
"La patria, tal y como la entendían los griegos y los romanos, era esencial y radicalmente opuesta a lo que por tal entendemos en nuestros tiempos y sociedades modernos. Era una institución de origen y carácter religioso, equivalente a lo que hoy es la Iglesia, por no decir más santa que ella (...). Su poder era omnipotente y sin límites respecto de los individuos que se componía. (...) La patria así entendida era la negación de la libertad individual en la que cifran la libertad todas las sociedades modernas que son realmente libres" Alberdi (1996, p. 299).

Combatían verdaderamente por sus altares, por sus hogares, pro aris et focis (...). El amor a la patria era la propiedad misma de los antiguos" Alberdi (1996, p. 306).

Llama la atención el empleo de una analogía igualmente anacrónica como el de comparar las polis griegas o las ciudades romanas con el Estado moderno: el amor a la patria solo puede ser comprendido por nosotros los modernos si pensamos el amor que profesamos a nuestras propiedades privadas. En este punto, el propio Alberdi pone en evidencia con su símil cuál es el máximo valor que la civilización debe defender.

Aunque Alberdi no lo haga totalmente explícito, el despotismo de los omnipotentes Estados modernos tiene un ancestro bifronte: la imagen idealizada de la comunidad grecoromana y el absolutismo monárquico. Pero esta mezcla es mucho más peligrosa cuando se combina con la retórica encendida de la soberanía popular de cuño rousseauniano (Botana, 1997, p. 442, Alberdi 1996, p. 306). Para Alberdi en una línea de lectura que lo relaciona con Tácito y Guizot, la libertad individual moderna no es heredera de la libertad participación clásica. Sumada al espíritu igualador del cristianismo, nos encontramos con el progreso de la moderna civilización.

\section{Los usos políticos del patriotismo}

Pero Alberdi no se limita a precisar los usos conceptuales de la patria y tratar de interpretarlo sino que apunta explícitamente a los motivos por los cuales sus contemporáneos se muestran tan afectos a emplear este término sin problematizarlo. Para indagar acerca del segundo uso de 'patria' en este texto es necesario preguntarse, siguiendo a Skinner (2005), ¿cuál es la intención de Alberdi al realizar esta "historia conceptual" de la noción de 'patria'? Como lo hace explícito el autor, lo que se propone es cuestionar el mal uso que hacen de la misma sus contemporáneos.

Esto nos lleva a dar cuenta de que, en la postulación de una genealogía particular para este término, Alberdi está tomando posición en la lucha política argentina. Se está dirigiendo a sus adversarios, al menos desde 1852 en adelante, que hicieron de la apelación a la 'patria' una reivindicación de la política facciosa. En este lenguaje político, donde lo teórico y lo práctico están totalmente imbricados, podemos observar cómo los dos niveles coinciden en una misma operación. Para evitar que, con buenas intenciones (como los patriotas de Mayo), o malas (¿los mitristas?, ¿los porteñistas y neo-rosistas?, ¿Sarmiento?), la 'patria' sea convocada para justificar una apropiación facciosa del poder que limite el goce de la libertad, y que produzca y reproduzca los conflictos internos que interfieren con la seguridad individual, es necesario hacer desaparecer la patria del vocabulario político. 
Pero ¿quién podrá reemplazarla? La 'nación', pero no ya en su sentido romántico, sino más bien en su acepción liberal. La nación civil de Adam Smith, es decir, la nación de la riqueza, del desarrollo capitalista, de la autorregulación social. Una nación cuyo horizonte de expectativas será diluirse en la civilización universal que por obra de la mano invisible de la cooperación comercial hará que el político se torne innecesario (Alberdi 1996, pp. 311, 317; Alberdi 2003, pp. 97-99).

\section{La nación civil desplaza al civismo}

Esta conclusión no se comprende si no se reponen algunas de las hipótesis principales de El Crimen de guerra. Además del ataque directo a la política exterior mitrista en el contexto de la guerra con el Paraguay, Alberdi percibe que en la propia Europa la política bismarkeana y la guerra franco prusiana ponen de manifiesto una cara oculta del progreso civilizatorio. Aquellas naciones que Alberdi tanto admiró en su juventud demuestran su fracaso no solo para resolver la cuestión social, situación que el jurista tucumano había observado en su viaje en la década de 1840, sino tampoco encuentran instituciones adecuadas para terminar con el mal endémico de la guerra. Y la génesis de ese mal Alberdi (El crimen, 2003, pp. 23-29) la encuentra en un tópico que recupera y desarrolla el filósofo italiano Espósito (1999, pp. 45-6) muchos años después: la convergencia etimológica en el griego entre polis (comunidad política) y polemios (guerra) que hace posible afirmar que la guerra es el fundamento último de la politicidad occidental. Es el Derecho de Gentes romano, inspirador del Derecho Internacional moderno, el que consagra esa visión con su odio al extranjero, una idea egoísta del poder y la apología de la supremacía del propio Estado, que hacen dejar de lado la doctrina cristiana, permitiendo a un colectivo de hombres eliminar a otros (Alberdi, El crimen, 2003, pp. 33, 67) ${ }^{9}$. Alberdi se pregunta si es un crimen matar a un individuo, ¿por qué no lo es cuando una entelequia llamada "soberano" se adjudica el derecho de hacerlo? Para solucionar este problema y la posibilidad eventual de guerra de todos contra todos en el sistema internacional de nacionales, Alberdi (2003, pp. 31, 45) recurre a una solución iusnaturalista: el juez neutral. Pero sabe, como el Kant de La Paz perpetua a quien menciona, que para que este sistema funcione, es necesario que exista una unidad garante de su aplicación, algo así como los Estados Unidos de la Humanidad. Para Alberdi (2003, p. 59), lo que impide el arribo de una civilización universal o del pueblo-mundo que ponga fin a la era bélica que Grocio y Adam Smith han profetizado, es el interés de los gobiernos (o de los gobernantes), que no quieren que se haga explícita la verdad de que, en el fondo, son innecesarios. La autorregulación social basta por sí misma para la prosperidad real de las naciones.

Es notable cómo Alberdi apunta a una de las facetas posibles de las posteriores derivas que tendrá la versión política de la nación en los nacionalismos del siglo XX pero que descuida otra que lo interesó en su juventud: el esencialismo cultural. 
En su lectura, Alberdi recurre al tópico liberal smithiano y constaniano donde el comercio por lógica y desenvolvimiento natural debe destruir los instintos belicosos de los pueblos. La eventual razón de que esto no suceda está en la propia clase política que se beneficia con esta inclinación belicosa para reafirmar su necesidad. Cabe preguntarse hasta qué punto este argumento no se contradice con la necesidad de un poder central institucionalizado como condición de posibilidad del desarrollo civilizatorio argentino planteado en Las Bases. Sin duda, lo hace, o al menos lo tensiona. Lo interesante es que, incluso en sus últimos años donde su liberalismo económico es una verdadera profesión de fe, Alberdi no abandona totalmente la eventual necesidad, al menos en el caso de una civilización inconclusa como la Argentina, de un soberano-presidente, que como primus inter pares genere desde la política las condiciones de posibilidad para que la sociedad civil sea posible.

En el Fragmento..., más allá de las tensiones entre 'patria' y 'nación', no se puede decir que ambos conceptos se piensen como contrarios asimétricos. Todavía parece posible una reconciliación o, mejor dicho, la posibilidad de supervivencia de cierto "halo" de sentimiento patriótico. Más de cuarenta años después, la 'patria' se transforma en el contrario asimétrico de la 'nación civil' que, tanto en su interior como en su inserción en el contexto internacional, solo aspira a consagrar la cooperación espontánea entre individualidades.

Pero este punto de llegada requiere de un doble camino. Un primer camino es conceptual, y es el que hemos recorrido. Allí se observa, por una parte, la tendencia a reafirmar una contraposición sutilmente presente en los textos juveniles entre la 'patria' como ideal guerrero anacrónico y la 'nación' como una proyección futura, sea cultural o bien económica. Pero, por el otro, también persiste, sobre todo en los textos literarios y en los comentarios críticos o polémicos con los adversarios políticos, un sentido sentimental del patriotismo, que lo identifica con el honor personal de haber sido fiel a sí mismo y a sus principios. El segundo camino, que apenas hemos esbozado, se encuentra en los modos de decir: en el uso de los recursos retóricos y enunciativos. En los textos trabajados, particularmente, prima el uso de figuras tales como la antítesis o el símil y la comparación, pero con una tendencia a deslizarlas a un plano metonímico, donde la causa o el origen (el patriotismo antiguo) tiñen el significado conceptual. Aunque no tan notable en el Fragmento..., tanto en La Omnipotencia... como en El Crimen de Guerra, así como también en los escritos póstumos sobre Mitre y Sarmiento, en la pieza teatral El Gigante Amapolas, o bien en la alegoría contra-utópica Peregrinación Luz de Día existe un juego irónico que a veces linda con el sarcasmo en la calificación del patriotismo de los otros. Con estos recursos retóricos, temáticos y enunciativos Alberdi define no solo su posición intelectual y política respecto a la 'nación' como tema de reflexión sino también desde qué lugar enunciativo él construye un discurso de nación donde la civilidad y la civilización desplazan poco a poco al civismo. 


\title{
III. Sarmiento: la revolución argentina y el enigma de la nación
}

\author{
"Se sabe: civilización/barbarie. Toda sociedad que necesita \\ organizarse debe reposar en una metáfora". \\ David Viñas, De Sarmiento a Dios
}

El vínculo conflictivo entre el civismo -heredero de la libertad política de la tradición republicana antigua y moderna-, y la civilidad -asociada con la "domesticación" política y económica de las costumbres "bárbaras" de una población marcada por la experiencia colonial-tendrá efectos directos en la sociabilidad y en las luchas políticas que recorren el siglo XIX argentino, y efectos duraderos que vuelven ambivalente el legado de la república. Para Alberdi, la civilización terminará imponiéndose en los hechos, moldeando nuevos hábitos en la natural arcilla del suelo nativo, pero también derrotando la antigua virtud cívica por la moderna virtú industriosa de los inmigrantes implantados.

Para Sarmiento, la república representa el orden político que expresa el más alto logro de la civilización moderna, que será realizable entre nosotros con la conjugación de nuevas instituciones y la construcción de nuevos sujetos. De allí que la oposición entre la civilización y la barbarie sea la matriz interpretativa del pasaje del mundo colonial al mundo moderno, y que la educación para formar ciudadanos resulte vertebral en la constelación de ideas que conforman su obra política.

Si en Hispanoamérica la república era una tarea, la singularidad de la misma suponía no solo el reemplazo de un régimen político que había caducado sino también la necesidad de instituir la nación en el antiguo territorio del virreinato. A diferencia de los países europeos en los que la formación del Estado-nación fue producto de un largo proceso de "umbral" incierto que fue el zócalo de la legitimidad de la república, la nación se impone entre nosotros más bien como un resultado del orden político que se buscaba instituir. La historia misma del término (y del concepto de nación) entre nosotros da cuenta de ese conflicto político singular.

Como hemos sostenido al inicio de este trabajo, la nación es más una idea que se va configurando en los proyectos políticos que se disputan la futura organización de la república. De este modo, podemos perfilar la idea sarmientina de la nación (adjetivada civilizada y cívica) en la constelación de sus principales temas y obstinaciones, en los enigmas e interrogantes que lo siguieron a lo largo de su vida, en el modo como proyectó en sus escritos políticos el presente, el pasado y el futuro de la Argentina.

\section{La Revolución de la Independencia argentina}

El primer punto es el significado de la Revolución de la Independencia argentina, a la que Sarmiento dedica un capítulo de Facundo, puesto que, en el discurso de esta generación, la nación surgía de la revolución, en ruptura radical con todo lo anterior. Sarmiento lo expresa de modo elocuente en el Discurso a la Bandera, dedicado al general Belgrano, 
"la patria como la bandera -dice-surge inventada de la nada colonial". Se trataba para él de construir una sociedad posrevolucionaria, a distancia de las instituciones y los hábitos que había dejado el pasado colonial, y en proximidad con los modelos franceses leídos en Cousin y en Guizot, Michelet, Leroux o Tocqueville: el Estado-nación, principio de centralización en el orden temporal, y la libertad y la igualdad, principios de despliegue del espíritu humano en el orden espiritual. Principios que son contrarios pero que se conjugan en el gobierno representativo, en el cual se realiza históricamente la esencia de la civilización. En ese sentido, la historia tiene una dirección ineluctable porque es la realización de una idea.

En ese marco construye un relato conceptual, en el cual el término revolución solo será aplicado a los movimientos cuyo fin es la libertad. En el mismo sentido, la nación que resulta será 'cívica' porque se funda en la libertad bajo el respeto de la ley, oponiéndose al despotismo y al arbitrio de un caudillo, el jefe incuestionable que reproducía las formas tradicionales de la dominación política. La revolución es así "el punto en el que nuestro drama comienza" y constituye el enigma que se propone explicar (Facundo [1845] 1927, p. 95). Es un drama, porque a diferencia de la Revolución en América del Norte, que se vivía como heredera de una larga historia de luchas por la libertad, o de la Revolución en Francia, que fundaba un nuevo régimen y un nuevo sujeto político, la Revolución en Sudamérica había abierto las puertas a una interminable y sangrienta lucha civil. También será un drama por la incertidumbre del momento, que tornaba poco probable su éxito final. En esas sociedades donde el colonialismo español había marcado el territorio y los hábitos de sus gentes, la revolución solo podía ser comprendida por las ciudades; para la campaña, por el contrario, la revolución era "extraña y sin prestigio", porque era extranjera a su manera de vivir y ajena a sus necesidades. Para Sarmiento, las campañas pudieron comprender el símbolo exterior de la independencia de la corona, pudieron comprender y valorar la separación de la tutela, porque correspondía con su propio espíritu libertario, pero no habían comprendido la revolución en su significado de libertad y responsabilidad del poder. El efecto inesperado de la revolución fue convertirse en expresión del carácter propio de esos hombres del país interior que Sarmiento no duda en comparar con los antiguos espartanos, por la disposición guerrera y la antipatía a la autoridad. Así, el movimiento revolucionario, que había comenzado en Buenos Aires, cambia de forma con la adhesión de las campañas pastoras. Se abre paso un elemento 'heterogéneo', que habiendo ingresado a la vida pública en las luchas de la independencia, se vuelve contra el ejército patriota y contra la vida de las ciudades. Este es el enigma a resolver.

La explicación que da en Facundo es conocida: "la revolución puso en contacto dos sociedades que habían coexistido sin conocerse [...]”. Civilización y barbarie será la fórmula acuñada por Sarmiento para presentar esa primera matriz explicativa de los males políticos que quería interpretar, y que despliega en una serie de figuras -'la ciudad' y 'las campañas pastoras', las tradiciones 'bárbaras' legadas por el dominio colonial y la vida en sociedad, con sus lazos de civilidad- en las que proyecta su visión del pasado, del presente y del provenir de la Argentina, desde los principios de una razón que se despliega en la historia. 


\section{Una filosofía de la historia}

No podrían entenderse estas afirmaciones sin el trasfondo de una filosofía de la historia, impregnada de un hegelianismo tomado de Cousin o de Guizot. No es que Sarmiento haya sido un lector sistemático de los filósofos franceses a los que se refiere en su obra, pero la paternidad de esas ideas se muestra en el uso de los conceptos, las citas con las que se inician varios capítulos, o que están presentes en el cuerpo del texto (muchas veces en francés). De esas lecturas surge la interpretación de la historia como marcha de la humanidad hacia el progreso, porque la historia es el escenario de la realización de la razón, y los hechos solo se comprenden a la luz de ese movimiento necesario. Para Sarmiento, como en general para la generación romántica, la razón ha perdido la abstracción y el simplismo que tenía en el discurso de los unitarios, y ha echado raíces en el mundo de la historia y de la sociedad. De allí que Sarmiento recurra a la figura de Facundo Quiroga, el caudillo riojano cuyas incursiones habían dejado fuerte impronta en su memoria infantil, para explicar a partir de su biografía los motivos profundos de las luchas civiles argentinas. Cabe destacar que Facundo no es un individuo aislado, y los episodios que lo involucraron no tendrían relevancia histórica si su persona no expresara el carácter de un pueblo:

"En Facundo Quiroga no veo a un caudillo simplemente, sino una manifestación de la vida argentina tal como la han hecho la colonización y las peculiaridades del terreno [...] Facundo es la expresión fiel de una manera de ser de un pueblo, de sus preocupaciones e instintos; Facundo, en fin, siendo lo que fue, no por accidente de su carácter, sino por antecedentes inevitables y ajenos de su voluntad es el personaje histórico más singular, más notable, que puede presentarse a la contemplación de los hombres que comprenden que un caudillo que encabeza un gran movimiento no es más que el espejo en el que se reflejan en dimensiones colosales las creencias, las necesidades, preocupaciones y hábitos de una nación en una época dada de su historia" (Facundo 1927, p. 38).

La vida de un "grand homme" 10 es un punto de inserción de incontables aspiraciones, relaciones y prejuicios colectivos, pero también personifica el pensamiento y la acción que procura trasmitir por su decisión a la sociedad. Trazando su biografía, Sarmiento quiere demostrar que el caudillo no es otra cosa que la manifestación de la vida argentina tal como ha resultado de la colonización y de las peculiaridades del terreno.

Civilización y barbarie son opuestos irreconciliables y así han sido interpretados, pero leídos en clave de la filosofía de la historia, designan para Sarmiento momentos en la marcha general de la historia, testimoniando la racionalidad del proceso. Así, contra los publicistas como de Angelis que presentaban a Rosas como la expresión más pura

La idea del Grand homme, o del hombre representativo, la toma Sarmiento de Victor Cousin, y tiene su origen en la noción hegeliana del héroe como apoderado de un fin en el avance progresivo del espíritu universal. Así, su grandeza depende de su condición de representante del espíritu general de su pueblo. 
del americanismo, desarrolla su idea de la historia universal, en la cual las figuras de Facundo Quiroga o de Juan Manuel de Rosas (en el que todos verán su doble) encarnan el pasado y la regresión del progreso. Por eso sus días están contados. La muerte del caudillo riojano no es en su relato un episodio casual, es la revelación de la fuerza de la historia en los hechos humanos. Ante su asesinato, Sarmiento sentencia: "En Barranca Yaco no era la naturaleza quien lo esperaba, sino la historia" (Facundo 1927, p. 321).

Años más tarde, en la Memoria titulada "Espíritu y condiciones de la historia en América", leída el 11 de octubre de 1858, al ser nombrado Director de Historia, en el Ateneo del Plata, retoma esta idea al interpretar la evolución natural de la humanidad:

"La historia, hoy que la humanidad entera se ha puesto en contacto por el comercio, por los vapores, por la prensa, por el telégrafo, por el grabado, por las instituciones, hasta por la moda, no puede clasificarse para nosotros al menos, en la historia de Francia o de Inglaterra, como de Grecia y Roma en otros tiempos. La historia moderna, dice, no es la historia de nadie, testigo Santa Helena; ni la de una nación, testigo la América. La historia es la ciencia que deduce de los hechos la marcha del espíritu humano en cada localidad, según el grado de libertad y de civilización que alcanzan los diversos grupos de hombres y el mejor historiador del mundo sería el que colocase las naciones según la medida de sus progresos morales, intelectuales, políticos y económicos" ("Espíritu y condiciones de la historia en América" [1858] 1928, p. 30).

Así, el presente de las naciones hispanoamericanas será medido por Sarmiento según esa ley que la filosofía de la historia decimonónica llamó progreso -en virtud del cual algunos pueblos permanecen estacionarios, mientras otros crecen o declinan-aunque atenido a las modalidades de cada nación.

Controversias de la nación

En 1852, Sarmiento escribe en la Memoria presentada al Instituto Histórico de Francia:

"La Nación la constituyen actos deliberados del pueblo representado en asambleas, y hay de sus bases y condiciones constancia escriturada, porque es la inteligencia y la voluntad las que constituyen la asociación y no la tierra ni la sangre. Si todas nuestras leyes no obedecen a esta ley suprema, es que algo queda de la colonia, de las malas tradiciones antiguas y de los hábitos no regenerados" (OC, T. XXI, p. 106).

La frase es tan rica en contenido como elocuente en la expresión de las ideas en pugna. La nación queda identificada con la forma republicana de gobierno, y su legitimidad solo podrá estar en la representación y en el consenso basado en la vigencia de la ley para todos. La nación, tal como escribe Renan es "un consenso cotidiano", y solo ese reconocimiento mutuo en la ley podrá sostener los pilares de un mundo común, acorde con los principios de la libertad moderna. Queda afuera toda referencia de la nación 
a la tierra o a la sangre; las fronteras estarán en adelante balizadas por los valores del civismo y por la idea de una humanidad integrada en el horizonte de la civilización.

La visión sarmientina se opone entonces al americanismo que equiparaba la nación con "las malas tradiciones antiguas", marcadas por la inercia y la reiteración de los hábitos coloniales. Esta oposición se pondrá de manifiesto de un modo conflictivo frente al bloqueo francés del puerto de Buenos Aires, que había sido apoyado por los proscritos del rosismo. La actitud de los "jóvenes patriotas", motivada por el rechazo a Rosas y su gobierno, había escandalizado a la opinión pública americana, engrosando el poder del caudillo porteño que aparecía defendiendo el principio americano frente a las pretensiones de una potencia extranjera. En referencia a este episodio, Sarmiento escribe en Facundo que si el "americanismo" significaba "tradición española, inmovilidad, orgullo ignorante, fanatismo nacional, los emigrados son con razón antiamericanos" (Facundo 1927, p. 318). Si desde un punto de vista material califica el bloqueo como "un hecho oscuro y sin resultados históricos", simbólicamente representaba la guerra de dos principios irreconciliables que chocaban en el terreno de la historia. Así explica la postura asumida por el grupo de exiliados que reivindicaban los nuevos lazos sociales y políticos inaugurados con la revolución: "esa juventud, impregnada de las ideas civilizadoras iba a buscar en los europeos enemigos de Rosas sus antecesores, sus padres, sus modelos: el apoyo contra América, tal como la presentaba Rosas, bárbara como el Asia, despótica y sanguinaria como la Turquía, persiguiendo y despreciando la inteligencia como el mahometismo" (Facundo 1927, p. 328) ${ }^{11}$. Los proscritos -como los llamara Ricardo Rojas-, representaban para Sarmiento la comunidad del porvenir, el nuevo vínculo social que se ha desplazado del apego a la tierra, a la adhesión racional a la ley común. Sarmiento señala que los unía el interés común de "vivir bajo un gobierno racional, y preparar sus destinos futuros" (Facundo 1927, p. 322). Aquellos que habían dejado su tierra colocándose en situación de extranjeros componían las bases de una nueva comunidad racional de pertenencia, alineándose de ese modo con los republicanos del otro lado del Atlántico. En su interpretación, el bloqueo no es efecto de una lucha de conquista o de reacción entre dos naciones soberanas, ni una nueva intervención colonial. Para el sanjuanino son las fuerzas de la civilización y del progreso en lucha con las fuerzas regresivas de Rosas y su americanismo.

Pero también contra el americanismo de la Confederación que legitimaba los poderes locales plantea en Argirópolis ([1850] OC, T. XIII, 1913) la unidad del antiguo territorio colonial bajo la nueva forma nacional surgida de un Congreso Constituyente. En el capítulo II de la obra que lleva por título "Las Provincias Unidas del Río de la

11 La frase remite al tratamiento del extranjero en los primeros momentos de la Revolución francesa. En concordancia con el horizonte cosmopolita heredero de la ilustración, el proyecto revolucionario borra las fronteras entre nacionales y extranjeros, instalando la idea de una fraternidad universal. En ese marco, la Asamblea Nacional de 1789 muestra una escena donde interlocutores extranjeros y diputados franceses, trabajando juntos por la libertad francesa, trabajaban por el progreso del universo, instalando la idea de una fraternidad universal. Cfr. Sophie Wahnish (1997). 
Plata, el Paraguay y la República del Uruguay" sostiene: "No es solo la cuestión de la Confederación Argentina la que se debate, sino la de las antiguas Provincias Unidas del Río de la Plata. Son los intereses de estas 'provincias confederadas' las que deben por sí mismas llegar a un advenimiento y acuerdo para gozar 'de igual a igual' las ventajas del comercio europeo". (Argirópolis 1913, p. 30). Lo que está en juego en esta propuesta es la conformación del territorio según la tendencia moderna de la federación que había visto en los Estados Unidos. La isla Martín García, situada en la puerta de entrada del Plata, se le figura marcada por la Providencia para ocupar el lugar de capital. Allí debería reunirse el Congreso constituyente. En sus Cartas Quillotanas, Alberdi escribe a propósito del proyecto de Argirópolis: “¿Cómo tener un congreso libre e independiente de los gobiernos de nuestro suelo, o bien sea del caudillaje?Colocándolo en el aire, sin duda: pero como eso es imposible, se le podría colocar en una isla, que siendo argentina, no estuviese en poder de los gobiernos argentinos: en Martín García, v.g., que entonces estaba en poder de los franceses" (Cartas Quillotanas 2005 , p. 125). En esta cita contenida en la inflamada polémica que mantuvieron después de Caseros, Alberdi ironiza haciendo hincapié en el componente utópico del proyecto sarmientino, que pretendía construir la unidad nacional desdeñando los materiales que componen el suelo de la república.

El debate sobre la organización nacional será otro revelador de las controversias por la definición de lo americano y, por lo tanto, del zócalo de la identidad nacional. Por las mismas razones que había disputado el americanismo defendido por los publicistas de Rosas, Sarmiento disputará ahora con Alberdi el lugar que éste le asigna al americanismo en la formación de la autoridad política. Si bien Alberdi, como quedó expuesto anteriormente, superó las posiciones filosóficas de su juventud adhiriendo a los argumentos doctrinarios después de la Revolución de Julio en Francia, en la polémica constitucional se mantiene americanista en la búsqueda del sustento histórico de la autoridad soberana que dé unidad a la nación. Defendiendo, frente a un Sarmiento devenido adversario, el rol de las campañas pastoras en el desarrollo argentino, afirma que "en Sud América el sentido común está más cerca de la realidad inmediata y palpitante, que de los libros que nos envía Europa del siglo XIX [...]" (Cartas Quillotanas 2005, p. 106). Para Sarmiento, la cuestión será, por el contrario, ser americano sin adherir a ese americanismo. Botana opina sobre la querella: "Sarmiento concluye adhiriendo a la teoría del transplante institucional, Alberdi defendiendo una teoría fuertemente arraigada en la tradición colonial" (Botana 1983, p. 340).

Sin pactos con el antiguo régimen, el punto de partida del nuevo orden no podía estar, para Sarmiento, sino inscripto en esa radical mutación democrática que inicia el mundo moderno. Sin embargo, en su programa, la democracia no se confunde con el poder espontáneo de las masas populares de las que desconfiaba. El programa que sostuvo, difundió y defendió a lo largo de toda su existencia consistió en regenerar la Argentina por medio de instituciones democráticas, inmigración europea, educación popular, reformas agrarias y económicas y tolerancia religiosa. Estaba persuadido de que era en las ideas y sentimientos nacionales que debía operarse una profunda revolución para torcer el destino de los pueblos inmovilizados. 
Finalmente, hagamos una referencia a la definición del término civilización que menciona en Viajes, citando el diccionario Salvá y tomando distancia de la Real Academia que -aclara- "no hace fe hoy": "[La civilización] es "aquel grado de cultura que adquieren pueblos i personas, cuando de la rudeza natural pasan al primor, elegancia y dulzura de voces i costumbres propios de jente culta". Sin embargo, esta acepción corresponde para Sarmiento al término civilidad, pues el refinamiento de las costumbres no agota el sentido de un proceso que también supone la perfección moral y el desarrollo de las fuerzas materiales para someter la naturaleza a su uso.

"Para mí, el mayor número de verdades conocidas constituye solo la ciencia de una época; pero la civilización de un pueblo solo puede caracterizarla la más extensa apropiación de todos los productos de la tierra, el uso de todos los poderes inteligentes y todas las durezas materiales, a la comodidad, placer y elevación moral del mayor número de individuos" (Viajes...1996, p. 301).

Varios intérpretes han señalado la correspondencia del pensamiento sarmientino con la noción de civilización acuñada en la filosofía de la historia francesa del siglo XIX. Su visión de la civilización como un cúmulo de conquistas materiales y morales, de bienes y de derechos, de facultades y comportamientos individuales y la extensión de sus logros al mayor número confirman no solo la idea de la perfectibilidad humana y la creencia en la razón, sino también el sentimiento de misión que impulsaba su proyecto político. Por otra parte, el uso del término civilización y la tensión tropológica contenida en la dicotomía, refuerzan el juicio negativo sobre su opuesto, la barbarie. En ese marco, su idea de nación cívica está lejos de ser un concepto unívoco. Por el contrario, ésta se fue forjando en la conjunción de ideas y de impulsiones de su puesta a prueba en la realidad.

\section{A modo de conclusión}

Para concluir nuestro análisis de la idea de nación cívica -y de la constelación conceptual de civilización, civismo y civilidad-que se perfila en los proyectos de Alberdi y de Sarmiento, quisiéramos considerar la posición de enunciación de estas construcciones discursivas.

En la mayoría de los textos, escritos en Argentina o fuera de su suelo, Alberdi pretende proclamarse como un intérprete a la distancia, física, pero sobre todo espiritual, de los problemas argentinos que le permite colocarse si no por encima, al menos por fuera de los partidos en pugna. Esta operación tiene, sin embargo, una fisura que queda bien explícita en un texto escrito en el exilio chileno, pero que persiste implícitamente en los trabajos analizados aquí. En La República Argentina 37 años después de su revolución de Mayo, Alberdi asume la voz de la nacionalidad argentina cuando habla. Poco después se aleja de este fervor para adoptar el punto de vista de quien desmitifica a los falsos apropiadores de este sentimiento, que quieren transformar en propias las glorias de la patria (en este caso, Rosas). Por ende, hay en el plano enunciativo del discurso de Alberdi sobre la 'nación' una dialéctica compleja entre compromiso y distanciamiento, que pone en el centro de la escena su concepción del intelectual y el tipo de factores (sociales, 
económicos y, en menor medida, políticos) que destaca a la hora de interpretar la realidad argentina y recomendar un curso de acción en tal sentido. De esta manera, Alberdi refuerza un dispositivo enunciativo que se "muestra" con total claridad en sus textos literarios como Peregrinación o El Gigante: cuando él habla, es la verdad la que toma, directa o indirectamente, la palabra.

Sarmiento es un hombre de acción y su vida estará entrelazada a las experiencias políticas que signaron los momentos fundacionales del Estado nación argentino. Nacido el año de la Revolución de Mayo fue publicista, maestro, director de escuela, senador, gobernador de la provincia de San Juan, presidente la nación. Como escribe Ricardo Rojas (1945, p. X) en la biografía que le dedica, "Sarmiento escribió mucho, pero sus escritos no nacen de recreación estética ni de abstracción filosófica sino de necesidad política, pues son crónicas de su ambiente y memorias de su propia existencia". Su posición de enunciación está lejos de corresponder con la objetividad del historiador o con la universalidad del filósofo. Sarmiento habla siempre desde el yo -lo que le valió en su época el apodo de "Sr. Yo"- haciendo pasar el episodio histórico por el prisma de su experiencia. Precisamente su género privilegiado será la biografía, la de los caudillos Facundo Quiroga o Félix de Aldao, que utiliza para representar el estado de una sociedad que despierta de la "siesta colonial", o su propia biografía y la de su linaje familiar que utiliza para legitimar su lugar en el futuro de la nación moderna que delinea en sus proyectos. También por eso, cada crítica o incomprensión es una afrenta que el hombre de acción no puede dejar pasar. Sin embargo, en un texto fundador de la nación cívica de Sarmiento como lo es Argirópolis, su pluma es mucho más distanciada, y en Conflicto y Armonía de las Razas en América, intentará utilizar las categorías de una incipiente ciencia social para desatar con el pensamiento los mismos nudos que quiso partir con la lucha.

Por eso, podemos concluir con la siguiente paradoja. Si la nación civil de Alberdi se quiere legitimar desde la distancia física o intelectual con la lucha política, su patriotismo sentimental lo fuerza a acercarse al plano más personal de ese mundo. La nación cívica de Sarmiento, por su parte, se construye en un espacio de intersección entre el compromiso directo con la acción política y las ambiciones personales que conlleva, y la vocación de comprender aun aquello que hace obstáculo a la realización del propio proyecto.

\section{Referencias bibliográficas}

Alberdi, J. B. [1871] (1916), Peregrinación de Luz del Día o Viajes y aventuras de la Verdad en el Nuevo Mundo. Buenos Aires: La Cultura Argentina.

[1842] (1920), "El gigante Amapolas y sus formidables enemigos o sea fastos dramáticos de una guerra memorable", Obras selectas. Tomo 1, nueva edición ordenada, revisada y precedida por una introducción por Joaquín V. González. Buenos Aires: Librería la Facultad de Juan Roldán.

Hachette.

(1955), Fragmento preliminar al estudio del derecho. Buenos Aires: 
(1995) “La república Argentina 37 años después de su Revolución”. Halperin.

(1996), "La omnipotencia del estado es la negación de la libertad individual", en Terán, Óscar, Escritos de Juan Bautista Alberdi: El redactor de la Ley. Bernal: Universidad Nacional de Quilmes.

[1837] (1977) "Doble Armonía entre el objeto de esta institución, con una exigencia de nuestro desarrollo social; y de esta exigencia con otra general del espíritu humano", en Weinberg, Félix, El salón literario de 1837. Buenos Aires: Hachette.

(2002), Escritos póstumos. Tomos XI y XV. Buenos Aires: Universidad Nacional de Quilmes.

[1870], (2003) El crimen de la guerra. Buenos Aires: Librería Histórica.

Alberdi, J. B. y D. F. Sarmiento (2005), La Gran Polémica Nacional: Cartas Quillotanas - Las ciento y una. Buenos Aires: Leviatán.

Botana, N. (1997), La tradición republicana. Buenos Aires: Sudamericana.

Derrida, J. (1987), Nacionalidad y nacionalismo filosófico. Montevideo: XYZ ed.

Donghi, Tulio (1995), Proyecto y construcción de una nación. Buenos Aires: Ariel.

Echeverría, E. (1940). Dogma socialista. Edición crítica de Palcos, La Plata, Universidad Nacional de La Plata.

Espósito, R. (1999), El origen de la politica ¿Hannah Arendt o Simone Weil? Barcelona: Paidós.

González Bernaldo de Quirós, P. (1999), Civilité et politique aux origines de la nation argentine. Paris: Publications de la Sorbonne.

Koselleck, R. (1993) Futuro pasado. Para una semántica de los tiempos históricos. Barcelona: Paidós.

Mayer, J. M. (1963), Alberdi y su tiempo. Buenos Aires: EUDEBA.

Rodríguez, G. (2008), “Alberdi: de la patria a la nación”, en Villavicencio, S. y Pacecca, M. I. (comp.), Perfilar la nación cívica en Argentina. Figuraciones y marcas en los relatos inaugurales. Buenos Aires: Editores del Puerto.

Rojas, R. (1945), El Profeta de la pampa. Buenos Aires: Losada.

Sarmiento, D. F. (1913) Argirópolis, o la capital de los Estados Confederados del Río de la Plata OC, T. XIII, Buenos Aires.

(1927), Facundo. Con introducción de Joaquín V. González. Buenos Aires: Ed. La cultura argentina (4 ${ }^{\mathrm{a}}$ reed).

(1996), Viajes por Europa. África i América, 1845-1847. Ed. crítica, coordinada por Javier Fernández, $2^{\mathrm{a}}$ ed. París: ALLCA XX/Ed. UNESCO.

Skiner Q. (2005), "Visions of Politics". Regarding Method. Volume I. Cambridge: Cambridge University Press.

Villavicencio, S. (2008), Sarmiento y la nación cívica. Ciudadanía y filosofías de la nación en Argentina. Buenos Aires: EUDEBA.

Wahnish, S. (1997), L'mposible citoyen. L'étranger dans le discours de la Révolution française. Paris: Éd. Albin Michel. 